\title{
"Short" double balloon enteroscope for endoscopic retrograde cholangiopancreatography with conventional sphincterotomy and metallic stent placement after Billroth II gastrectomy
}

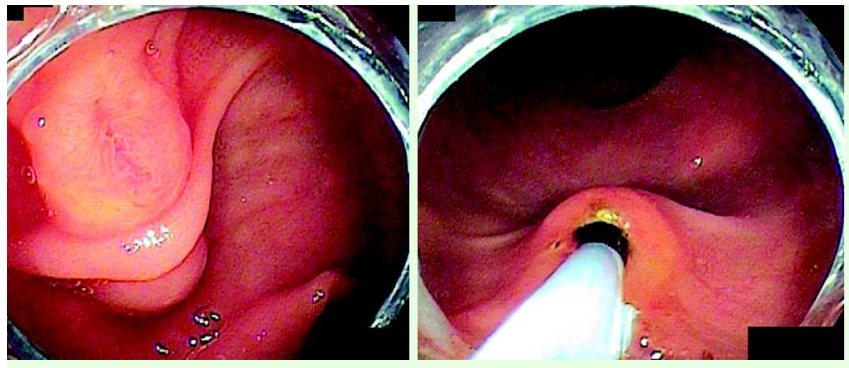

Fig. 1 Although the papilla is located at the 11 o'clock position in the visual field (left), the papilla can be moved to the 6 o'clock position by keeping the overtube balloon inflated and rotating the enteroscope, resulting in successful cannulation (right).

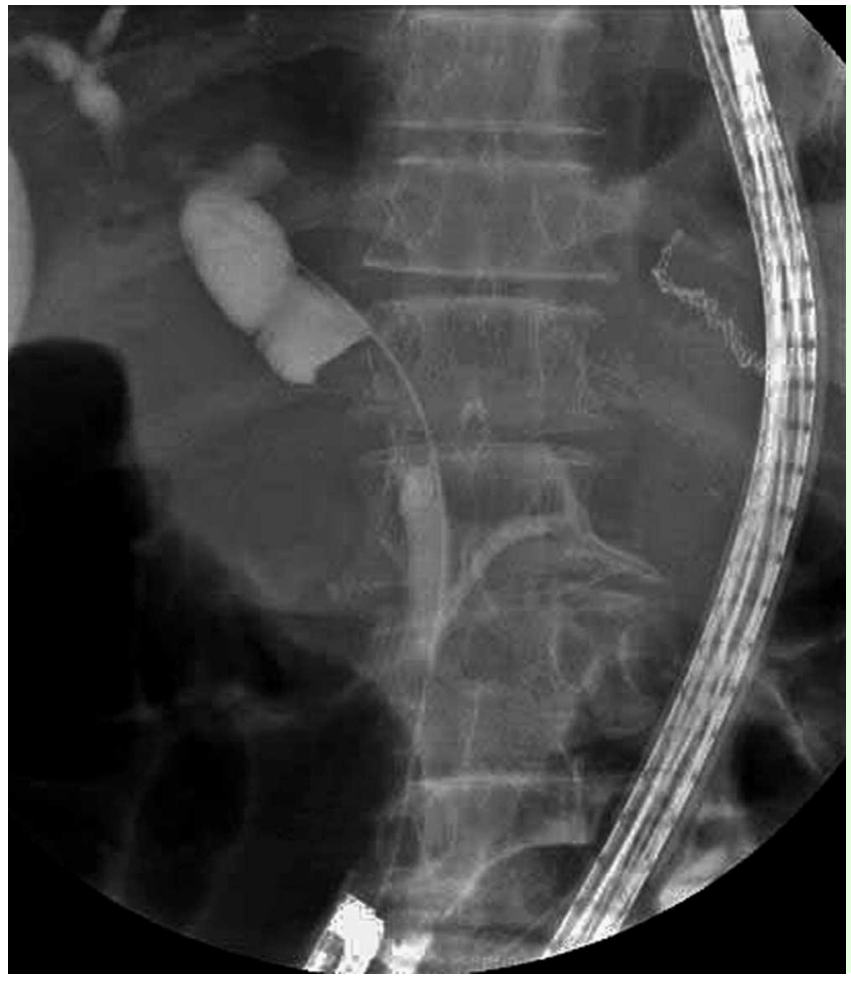

Fig. 2 After deep cannulation, a stricture is visualized in the common bile duct.

During endoscopic retrograde cholangiopancreatography (ERCP) in patients with Billroth II gastrectomy, identifying the afferent loop, access to the papilla, and cannulation in the inverted papilla are difficult [1]. With the advent of the double balloon technique, ERCP in such patients can be performed [1], but conventional accessories cannot be used because of short accessory lengths [ $1-5]$. We carried out double balloon enteroscopy for ERCP (DB-ERCP) with a "short" enteroscope in a patient with Billroth II gastrectomy, and successfully performed ERCP with conventional sphincterotomy and metallic stent placement.

A 79-year-old man, who had undergone Billroth II gastrectomy for gastric cancer, presented with jaundice. Computed tomography (CT) showed a tumor in the common bile duct causing biliary tree dilatation. We performed DB-ERCP with a "short" enterosope, EC450-BI5 (FujinonToshiba, Osaka, Japan), which has a 2.8 mm working channel and a $152-\mathrm{cm}$ working length and for which conventional ac-

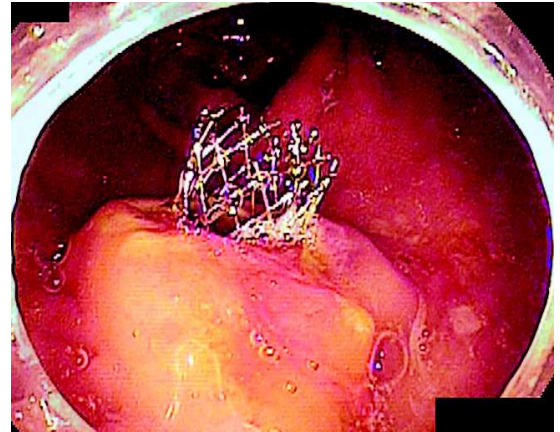

Fig. 3 After endoscopic sphincterotomy with a conventional sphincterotome, a metallic stent is easily inserted across the stricture.

cessories are available. The enteroscope successfully reached the duodenal stump. Despite the inverted papilla being located at the 11 o'clock position in the visual field, the papilla could be moved to the 6 o'clock position by keeping the overtube balloon inflated and rotating the enteroscope, resulting in successful cannulation (৫ Fig. 1). The diagnosis of malignant biliary structure caused by recurrent gastric cancer was made based on imaging and histologic studies ( $\bullet$ Fig. 2). After endoscopic sphincterotomy with a conventional sphincterotome, a metallic stent was easily inserted across the stricture with uneventful recovery ( $\bullet$ Fig. 3 ).

ERCP is technically challenging and often unsuccessful in patients with altered gastrointestinal anatomy [1,3-5]. Several authors have performed DB-ERCP in such patients, with the use of a standard EN$450 \mathrm{P} 5 / 20$ enteroscope or a therapeutic EN-450T5 enteroscope [1-5]. Because both enteroscopes have a working length of $200 \mathrm{~cm}$, specialized custom-made or very limited accessories are available [1-5]. We therefore recommend the "short" enteroscope for diagnostic and therapeutic ERCP in patients with altered gastrointestinal anatomy because all conventional accessories are available.

Endoscopy_UCTN_Code_TTT_1AR_2AK Endoscopy_UCTN_Code_TTT_1AR_2AZ 
M. Shimatani, M. Matsushita,

M. Takaoka, T. Kusuda, N. Fukata,

M. Koyabu, K. Uchida, K. Okazaki

Third Department of Internal Medicine,

Kansai Medical University, Osaka, Japan

\section{References}

1 Chu YC, Su SJ, Yang CC et al. ERCP plus papillotomy by use of double-balloon enteroscopy after Billroth II gastrectomy. Gastrointest Endosc 2007; 66: 1234-1236

2 Maaser C, Lenze F, Bokemeyer $M$ et al. Double balloon enteroscopy: a useful tool for diagnostic and therapeutic procedures in the pancreaticobiliary system. Am J Gastroenterol 2008; 103: 894-900
3 Mönkemüller K, Bellutti M, Neumann H et al. Therapeutic ERCP with the double-balloon enteroscope in patients with Roux-en-Y anastomosis. Gastrointest Endosc 2008, 67: $992-996$

4 Aabakken L, Bretthauer M, Line PD. Doubleballoon enteroscopy for endoscopic retrograde cholangiography in patients with a Roux-en-Y anastomosis. Endoscopy 2007; 39: $1068-1071$

5 Emmett DS, Mallat DB. Double-balloon ERCP in patients who have undergone Roux-en-Y surgery: a case series. Gastrointest Endosc 2007; 66: 1038 - 1041
Bibliography

DOI $10.1055 / s-0028-1103461$

Endoscopy 2009; 41: E19-E20

(c) Georg Thieme Verlag KG Stuttgart · New York . ISSN 0013-726X

\section{Corresponding author}

\section{Matsushita, MD}

Third Department of Internal Medicine Kansai Medical University

2-3-1 Shinmachi

Hirakata

Osaka 573-1191

Japan

Fax: +81-72-8042061

matsumit@hirakata.kmu.ac.jp 